ANL- 6585

Radiation Effects on Materials (TID-4500, 17th Ed.) AEC Research and

Development Report

AR GONNE NATIONAL LABORA TORY

9700 South Cass Avenue

Argonne, Illinois

POSSIBLE IMPLICATIONS OF THE DAMAGE BY RADIATION

IN THE STORAGE OF PROPELLANTS IN OUTER SPACE AND TENTATIVE METHODS FOR ITS MEASUREMENT

by

J.A. McMillan

Solid State Science Division

July 1962

Operated by The University of Chicago

under

Contract W-31-109-eng-38 


\section{DISCLAIMER}

This report was prepared as an account of work sponsored by an agency of the United States Government. Neither the United States Government nor any agency Thereof, nor any of their employees, makes any warranty, express or implied, or assumes any legal liability or responsibility for the accuracy, completeness, or usefulness of any information, apparatus, product, or process disclosed, or represents that its use would not infringe privately owned rights. Reference herein to any specific commercial product, process, or service by trade name, trademark, manufacturer, or otherwise does not necessarily constitute or imply its endorsement, recommendation, or favoring by the United States Government or any agency thereof. The views and opinions of authors expressed herein do not necessarily state or reflect those of the United States Government or any agency thereof. 


\section{DISCLAIMER}

Portions of this document may be illegible in electronic image products. Images are produced from the best available original document. 
TABLE OF CONTENTS

$\underline{\text { Page }}$

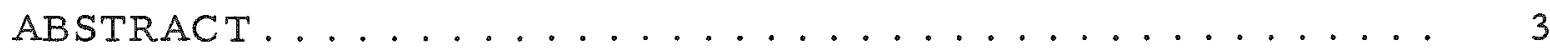

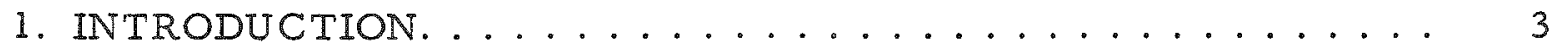

2. POSSIBLE IMPLICATIONS OF THE RADIATION DAMAGE . . . 4

2.1 Damage in the Liquid ................. 4

2.1.1 Radiolysis of Liquid Hydrogen Peroxide........ 4

2.1.2 Radiolysis of Liquid Hydrazine............ 6

2.2 Damage in the Solid ................... 7

2.2.1 Critical Concentration of Radicals........... 7

2.2.2 Thermal Behaviour of $\mathrm{H}$-bonded Glasses ....... 8

2.2.3 Radiation Behaviour of $\mathrm{H}$-bonded Glasses....... 10

2.3 Conclusions and Recommendations ............. 11

3. DAMAGE MEASUREMENT IN OUTER SPACE .......... 12

3.1 Radiation Environment in Outer Space ........... 12

3.2 Measurement of Radiation Damage by Paramagnetic

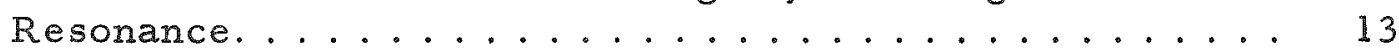

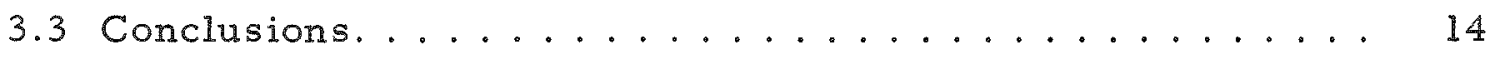

4. APPENDIX. DEFINITIONS AND UNITS ............ 16

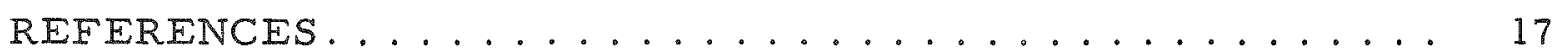




\title{
POSSIBLE IMPLICATIONS OF THE DAMAGE BY RADIATION IN THE STORAGE OF PROPELLANTS IN OUTER SPACE AND TENTATIVE METHODS FOR ITS MEASUREMENT
}

by

J. A. McMillan

\begin{abstract}
The damage by radiation that can be expected during the storage of hydrogen-bonded propellants in outer space is analyzed in terms of the available data on radiation levels. On this basis, the alternatives of storing the propellants as liquids or as solids, at low temperature, are discussed, and account is taken of recent results on their thermal behaviour obtained at this Laboratory. Vitreous states of aggregation of compounds that could crystallize spontaneously after long periods of irradiation are shown to present some hazards that can be prevented.

General considerations of radiation-damage detection in outer space are also made. Paramagnetic resonance is found to be of little use in view of the relatively low-dose levels. Solid-state devices are finally recommended.
\end{abstract}

\section{INTRODUCTION}

Radiation hazards in outer space may be classified into 3 categories, namely:
a) biological effects,
b) material damage, and
c) delayed effects (such as induced radioactivity).

Unless heavy shielding were feasible, which is not the case, each type of hazard must be approached in a different way, a procedure adding difficulties to the already complex pattern of space navigation.

Further analysis of the damage by radiation suggests consideration of 2 main and well-defined types of damage, namely:

i) failure and malfunction of devices, and

ii) decomposition by radiation. 
The purpose of this report is to analyze some of the implications of the decomposition of propellants as related to their storage in outer space.

An obvious question is how to store a liquid propellant, * i.e., as a liguid, or as a solid at low temperature. It should be noted in this respect that low-temperature storage presents problems that have been clearly considered in the case of liquid hydrogen.(I) It is also true, however, that radiolysis of a liquid would necessarily impose the adoption of zero-g venting systems, whose complexity is well known. Therefore, the optimum solution from the decomposition-by-radiation viewpoint may, or may not, be the optimum solution as suggested by other considerations and should be taken within the limited scope claimed above.

Well-known results in low and intermediate dose rate** radiation damage are:

I) The continuous-irradiation decomposition of a liquid proceeds until total destruction, especially if gaseous products are formed.

II) The decomposition of a solid at sufficiently low temperature proceeds until a dynamic-equilibrium damage concentration is established due to a balance between production and annealing processes.

The two cases will be discussed in some detail in Sections 2.1 and 2.2.

\section{POSSIBLE IMPLICATIONS OF THE RADIATION DAMAGE}

\subsection{Damage in the Liquid}

As pointed out above, radiolysis of a liquid proceeds until total destruction. The rate of decomposition depends on the dose rate and on the liquid composition. The radiation yield, however, expressed in $G$-units (number of radiolyzed molecules per $100 \mathrm{ev}$ absorbed, see Appendix), does not usually change by more than one order of magnitude. Values varying between 1 and 6 are frequent, although in the case of endothermic, unstable compounds the yield may be much higher because of secondary effects. In such an event, the $G$-value has little significance unless all other parameters (temperature, dose rate, viscosity, etc.) are adequately described.

\subsubsection{Radiolysis of Liquid Hydrogen Peroxide}

Considering only the formation of radicals, there are 2 main primary processes of radiolysis of the $\mathrm{H}_{2} \mathrm{O}_{2}$ molecule:

* Liquid propellants are here defined as propellants that are liquid at or near room temperature.

**By low and intermediate rates we mean rates that would not significantly raise the temperature of the material. 


$$
\begin{aligned}
& \mathrm{H}_{2} \mathrm{O}_{2} W-\mathrm{H}+\mathrm{HO}_{2} \\
& \mathrm{H}_{2} \mathrm{O}_{2} \text { WW- } 2 \mathrm{HO}
\end{aligned}
$$

The so-formed radicals, $\mathrm{H}, \mathrm{OH}$ and $\mathrm{HO}_{2}$, have a very short half-life in the liquid. They react among themselves to give molecular species, as in

$$
\begin{aligned}
& \mathrm{H}+\mathrm{H} \rightarrow \mathrm{H}_{2} \\
& \mathrm{H}+\mathrm{OH} \rightarrow \mathrm{H}_{2} \mathrm{O} \\
& \mathrm{H}+\mathrm{HO}_{2} \rightarrow \mathrm{H}_{2} \mathrm{O}_{2} \\
& \mathrm{HO}_{2}+\mathrm{OH} \rightarrow \mathrm{H}_{2} \mathrm{O}+\mathrm{O}_{2} \\
& \mathrm{HO}_{2}+\mathrm{HO}_{2} \rightarrow \mathrm{H}_{2} \mathrm{O}_{2}+\mathrm{O}_{2} \\
& \mathrm{OH}+\mathrm{OH} \rightarrow \mathrm{H}_{2} \mathrm{O}_{2},
\end{aligned}
$$

or with molecular species to yield radicals, as in

$$
\begin{aligned}
& \mathrm{OH}+\mathrm{H}_{2} \rightarrow \mathrm{H}_{2} \mathrm{O}+\mathrm{H} \\
& \mathrm{OH}+\mathrm{H}_{2} \mathrm{O}_{2} \rightarrow \mathrm{H}_{2} \mathrm{O}+\mathrm{HO}_{2} \\
& \mathrm{H}+\mathrm{H}_{2} \mathrm{O}_{2} \rightarrow \mathrm{H}_{2} \mathrm{O}+\mathrm{OH} .
\end{aligned}
$$

One of the most important characteristics of the radiolysis of $\mathrm{H}_{2} \mathrm{O}_{2}$ is the existence of the chain reactions:

$$
\begin{aligned}
& \mathrm{HO}_{2}+\mathrm{H}_{2} \mathrm{O}_{2} \rightarrow \mathrm{H}_{2} \mathrm{O}+\mathrm{OH}+\mathrm{O}_{2} \\
& \mathrm{OH}+\mathrm{H}_{2} \mathrm{O}_{2} \rightarrow \mathrm{H}_{2} \mathrm{O}+\mathrm{HO}_{2}
\end{aligned}
$$

which may lead to very high $G$-values.

The overall decomposition of $\mathrm{H}_{2} \mathrm{O}_{2}$ may be expressed by

$$
\mathrm{H}_{2} \mathrm{O}_{2} M M M-x \mathrm{H}_{2} \mathrm{O}+(1-\mathrm{x}) \mathrm{H}_{2}+\left(1-\frac{1}{2} \mathrm{x}\right) \mathrm{O}_{2}
$$

Interpretation of Eq. (14) is interesting. At the beginning, $x \approx 1$, and the overall radiolysis may be represented by

$$
\mathrm{H}_{2} \mathrm{O}_{2} \mathrm{MMM}-\mathrm{H}_{2} \mathrm{O}+\frac{1}{2} \mathrm{O}_{2}
$$

Once a significant amount of $\mathrm{H}_{2} \mathrm{O}$ is formed, the process of Eq. (15) competes with

$$
\mathrm{H}_{2} \mathrm{OWM}-\mathrm{H}_{2}+\frac{1}{2} \mathrm{O}_{2}
$$


giving rise to the complex process represented by Eq. (14). As the concentration of $\mathrm{H}_{2} \mathrm{O}_{2}$ decreases, the value of $\mathrm{x}$ becomes smaller and the ultimate effect of the irradiation is

$$
\mathrm{H}_{2} \mathrm{O}_{2} \mathrm{nuw}-\mathrm{H}_{2}+\mathrm{O}_{2} \text {. }
$$

Intermediate values of $x$ create an important problem: the formation of explosive mixtures of $\mathrm{H}_{2}$ and $\mathrm{O}_{2}$.

\subsubsection{Radiolysis of Liquid Hydrazine}

Considering, as in the case of $\mathrm{H}_{2} \mathrm{O}_{2}$, only the formation of radicals, the 2 main primary processes of radiolysis of the $\mathrm{N}_{2} \mathrm{H}_{4}$ molecule are

$$
\begin{aligned}
& \mathrm{N}_{2} \mathrm{H}_{4} \mathrm{Au}-2 \mathrm{NH}_{2} \\
& \mathrm{~N}_{2} \mathrm{H}_{4} \mathrm{MW}=\mathrm{H}+\mathrm{NH}_{2}-\mathrm{NH} .
\end{aligned}
$$

The so-formed radicals, $\mathrm{H}, \mathrm{NH}_{2}$, and $\mathrm{NH}_{2}-\mathrm{NH}$, have a very short half-life in the liquid state. They react among themselves to give molecular species, as in

$$
\begin{aligned}
& \mathrm{N}+\mathrm{H} \rightarrow \mathrm{H}_{2} \\
& \mathrm{H}+\mathrm{NH}_{2} \rightarrow \mathrm{NH}_{3} \\
& \mathrm{H}+\mathrm{NH}_{2}-\mathrm{NH} \rightarrow \mathrm{N}_{2} \mathrm{H}_{4} \\
& \mathrm{NH}_{2}-\mathrm{NH}+\mathrm{NH}_{2}-\mathrm{NH} \rightarrow \mathrm{N}_{2}+2 \mathrm{NH}_{3},
\end{aligned}
$$

or with molecular species, as in

$$
\begin{aligned}
& \mathrm{H}+\mathrm{NH}_{3} \rightarrow \mathrm{H}_{2}+\mathrm{NH}_{2} \\
& \mathrm{H}+\mathrm{NH}_{2}-\mathrm{NH}_{2} \rightarrow \mathrm{NH}_{3}+\mathrm{NH}_{2}-\mathrm{NH} \\
& \mathrm{NH}_{2}+\mathrm{NH}_{2}-\mathrm{NH}_{2} \rightarrow \mathrm{NH}_{3}+\mathrm{NH}_{2}-\mathrm{NH} .
\end{aligned}
$$

As in the case of $\mathrm{H}_{2} \mathrm{O}_{2}$, the radiolysis yield of hydrazine is increased by the chain reactions

$$
\begin{aligned}
& \mathrm{NH}_{2} \mathrm{NH}+\mathrm{NH}_{2} \mathrm{NH}_{2} \rightarrow \mathrm{NH}_{3}+\mathrm{N}_{2}+\mathrm{NH}_{2} \\
& \mathrm{NH}_{2}+\mathrm{NH}_{2} \mathrm{NH}_{2} \rightarrow \mathrm{NH}_{3}+\mathrm{NH}_{2} \mathrm{NH} .
\end{aligned}
$$

These self-sustained reactions explain the very high yield reported by Lucien in his study of the $\mathrm{X}$-ray radiolysis of anhydrous 
hydrazine.(2) Addition of small amounts of an appropriate scavenger could be expected to reduce the G-value by a large factor.

The process of Eq. (23) is likely to occur through the formation of the unstable tetrazane:

$$
\mathrm{NH}_{2}-\mathrm{NH}+\mathrm{NH}_{2}-\mathrm{NH} \rightarrow\left[\mathrm{NH}_{2}-\mathrm{NH}-\mathrm{NH}-\mathrm{NH}_{2}\right]
$$

that would undergo rearranging and splitting according to<smiles></smiles>

More complex reactions, as for example

$$
\mathrm{NH}_{2}-\mathrm{NH}+\mathrm{NH}_{2} \rightarrow \mathrm{NH}_{3}+\mathrm{N}_{2}+\mathrm{H}_{2} \text {, }
$$

this latter with the intermediate step of the unstable di-imide $H N=N H$, are also likely to occur.

As in the case of $\mathrm{H}_{2} \mathrm{O}_{2}$, all these reactions add up to an overall decomposition with variable coefficients:

$$
\mathrm{N}_{2} \mathrm{H}_{4}\left(\mathrm{MU}-\mathrm{x} \mathrm{NH}_{3}+\left(1-\frac{1}{2} \mathrm{x}\right) \mathrm{N}_{2}+2\left(1-\frac{3}{4} \mathrm{x}\right) \mathrm{H}_{2}\right.
$$

The knowledge of $\mathrm{x}$ may be important, since its value could be expected to vary with the addition of combustion regulators.

Radiolysis of mixtures of hydrazine and water, even for small concentrations of the latter, should obviously be expected to behave in a different manner because of secondary reactions with the radical $O H$.

\subsection{Damage in the Solid}

\subsubsection{Critical Concentration of Radicals}

The storage of radicals in a solid, even at low temperatures, is limited by spontaneous recombination above a certain critical value of the concentration. Should the concentration be higher, statistical recombination of any 2 radicals would warm up a region containing enough radicals to trigger a chain recombination, thus lowering the concentration to a value at which the chain reaction would no longer be self-sustaining. This effect has received theoretical (3) and experimental(4) consideration in the case of atomic nitrogen trapped in solid molecular nitrogen, indicating ca. $10^{-3}$ atoms per molecule as the critical concentration at $4.2^{\circ} \mathrm{K}$. The critical concentration has been found to vary somewhat with temperature in the case of ice, 
whose value at $77^{\circ} \mathrm{K}$ is $6 \times 10^{-4}$ OH radicals per molecule and less than 10 times higher at $4.2^{\circ} \mathrm{K},(5)$ but it seems to be practically independent of the dose rate in the low and intermediate ranges (see Figure 1).

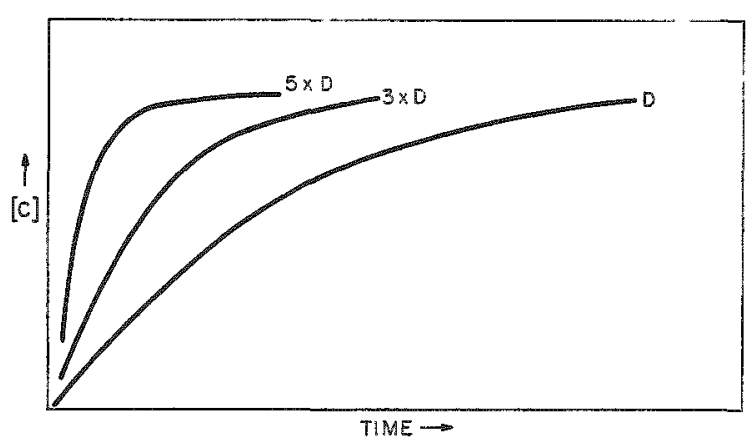

Figure 1. Constant-irradiation growth of radicals concentration $[\mathrm{C}]$ as a function of time for different dose rates $D$

Since the value of the critical concentration is mainly determined by the heat of recombination and by the specific heat and thermal conductivity of the lattice, it is clear that the critical value cannot change by more than one order of magnitude in different substances. The temperature at which recombination occurs, however, can be much higher, and some radicals can be stored indefinitely at room temperature. If it is taken into account that the recombination of radicals usually occurs with a heat release of 50 to

$100 \mathrm{kcal} / \mathrm{mol}$, the total energy stored may be, at most, $5 \%$ for a yield $(G$-value) of one pair of radicals per $100 \mathrm{ev}$ absorbed by the sample. In the case of ice, for example, if it be assumed that for the recombination, there is a heat release of $50 \mathrm{kcal} / \mathrm{mol}$, a matrix specific heat of $0.5 \mathrm{cal} / \mathrm{g}$, and a critical concentration at $77^{\circ} \mathrm{K}$ of $10^{-3} \mathrm{OH}$ radicals per molecule, i.e., ca. $5 \times 10^{-5} \mathrm{~mol} / \mathrm{g}$, the total recombination of the stored radicals (should it occur spontaneously) would raise the sample temperature approximately $5^{\circ}$.

Even if the recombination of radicals gave rise to a compound other than the parent one $-\mathrm{H}_{2} \mathrm{O}_{2}$ in the case of $\mathrm{H}_{2} \mathrm{O}, \mathrm{NH}_{3}$ in the case of $\mathrm{N}_{2} \mathrm{H}_{4}$ - this compound would accumulate to a certain degree, and the parent substance would remain with only minor changes in composition. The structural changes, however, could be expected to be significantly larger, as it will be seen in the following sections.

\subsubsection{Thermal Behaviour of Hydrogen-bonded Glasses}

A systematic investigation of the thermal behaviour of lowtemperature glasses is currently under progress in our Laboratory. The results obtained so far may be summarized as follows:

I. Typical H-bonded compounds - like oxygen and nitrogen hydrides, alcohols and amines - that can be obtained in the crystalline form can always be obtained in the vitreous state by either supercooling or collecting at low temperature from a molecular beam, or both.*

*It should be noted that most of the rocket propellants belong to this category, namely, hydrogen peroxide, hydrazine and its derivatives, etc. 


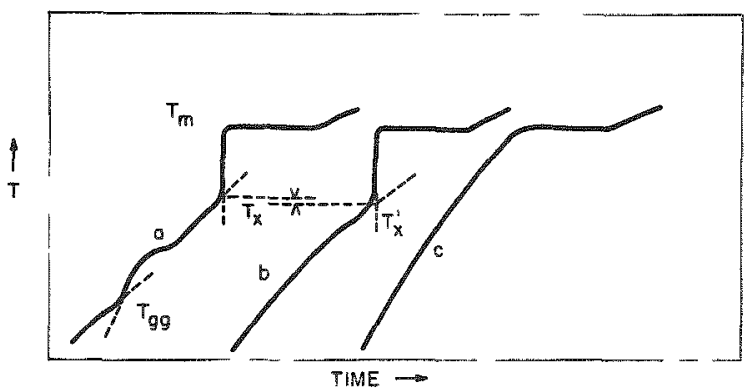

Figure 2. Warmup curves of solid ethanol:

a. supercouled at $77^{\circ} \mathrm{K}$,

b. supercooled and irradiated at $77^{\circ} \mathrm{K}$ and

c. crystalline ethanol
II. These compounds, when obtained in the vitreous state, crystallize spontaneously at a reproducible temperature $T_{\mathrm{X}}$ during warmup [see Figure 2(a)].

III. Crystallizable compounds that can easily be obtained in the vitreous state by supercooling exhibit a temperature $T_{X}$ such that the heat evolved during crystallization raises the sample temperature to the melting point, e.g., ethanol, isopropanol, $85 \%$-hydrazine hydrate, and $90 \%$ hydrogen peroxide.

IV. Compounds that can only be obtained in the vitreous state by low-temperature deposition in a vacuum exhibit a much larger difference between $\mathrm{T}_{\mathrm{x}}$ and the melting point temperature, e.g., methanol, water, and anhydrous hydrazine.

V. Mixtures of crystallizable compounds exhibit values of $T_{X}$ higher than those of the pure components, and there may be limits of composition within which crystallization cannot occur. In these regions, the extrapolated values of $\mathrm{T}_{\mathrm{X}}$ coalesce with the extrapolated values of the melting point (solidus curve in a solid solution) temperature (see Figure 3), e.g., 30\% to $70 \%$ n-butanol in methanol, $10 \%$ to $80 \% \mathrm{n}$-butanol in ethanol, wate $x$-hydrazine around the composition $\mathrm{N}_{2} \mathrm{H}_{4} \cdot 2 \mathrm{H}_{2} \mathrm{O}$, etc. A widely used glass-forming solvent, EPA, * exhibits these characteristics and gives on cooling a clear and permanent glass.

VI. In some cases, e.g., vitreous ice collected at $77^{\circ} \mathrm{K}$ from low-pressure vapour and ethanol rapidly cooled at the same temperature, a less exothermic though still

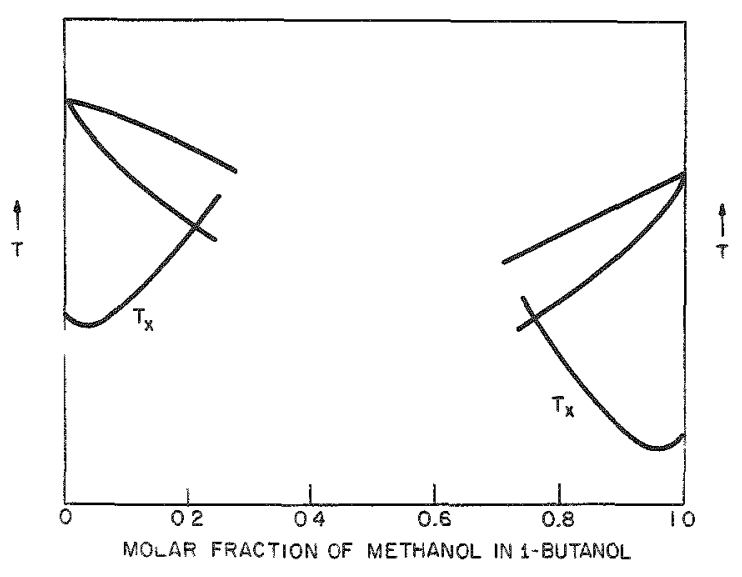

Figure 3. Phase diagram of methanol and n-butanol showing:

1) liquidus curve (upper curve),

ii) solidus curve (medium curve), and

iii) spontaneous crystallization curve noticeable irreversible transformation occurs near $100^{\circ} \mathrm{K}$ [see Figure 2(a)]. This effect has been attributed to formation of hydrogen bonds

* EPA composition is approximately: Diethyl ether, 5 parts; Isopentane, 5 parts; and Ethanol, 2 parts. The first 2 components do not even give a glass by supercooling; the mixture, however, is a perma. nent glass. 


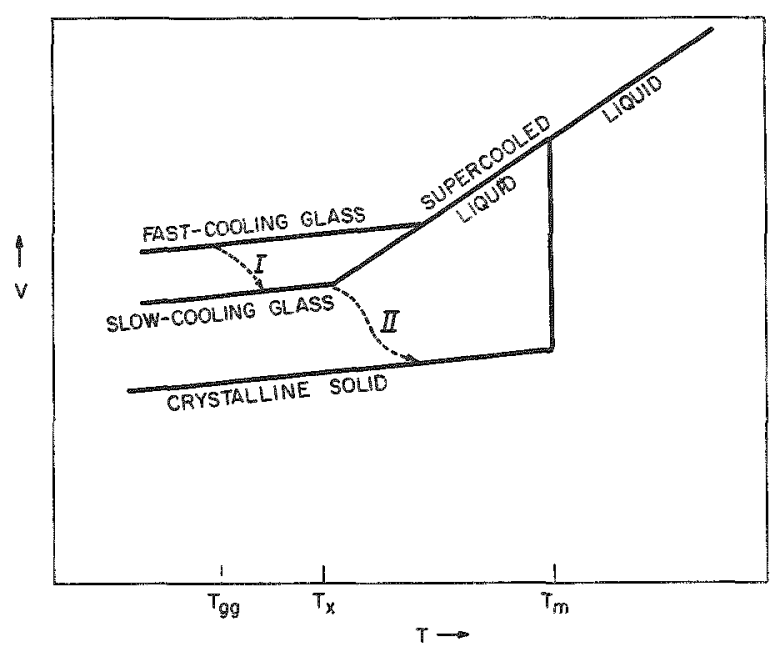

Figure 4. Typical volume-temperature diagram of a crystallizable glass

in the case of ice.(6) The nature of the phenomenon in the case of ethanol, and presumably in vitreous ice as well, can be understood from examination of the volume-temperature diagram of Figure 4. Rapid cooling takes place along the upper line, as indicated, creating a less stable glass that relases during warmup to a more stable network with release of energy (dotted curve I). The compound crystallizes at a higher temperature ( $T_{X}$; dotted curve II). This explanation accounts for the fact that concentrated aqueous solutions of hydrogen peroxide supercooled and stored at $77^{\circ} \mathrm{K}$ experience a rather slow transformation that occurs with visible volume contraction and is completed within hours. (7)

According to our experimental results, the characteristics summarized from I to VI, and especially the exothermic processes of crystallization and reordering, are significant from the point of view of the radiation damage. The relevant facts are:

i) damage annealing usually occurs around the reordering and crystallization temperatures, and

ii) dose rates above certain values can trigger reordering and crystallization without actual warming of the whole sample.

\subsubsection{Radiation Behaviour of Hydrogen-bonded Glasses}

Gamma irradiation of vitreous ethanol at a dose rate of ca. $10^{17} \mathrm{ev} / \mathrm{cm}^{3}-$ min at $77^{\circ} \mathrm{K}$ showed that the exothermic stabilization of the glass that occurs at ca. $100^{\circ} \mathrm{K}$ during warmup of nonirradiated samples does not take place after irradiation. This result indicates that the transformation has been triggered by the irradiation by a strictly local rise in temperature, since the bulk temperature of the sample during irradiation does not change appreciably. Such a dose rate of irradiation, however, is not enough to trigger crystallization. This latter fact may be due to either a too small local rise in temperature (less than $55^{\circ}$ yet still larger than $20^{\circ}$ ) or to the heat evolved by crystallization of small regions that would not be enough to warm the surroundings up to the temperature $T_{x}$. Higher dose rates would be expected to trigger crystallization. Should this be the case of hydrogen peroxide, and there are good reasons to expect a similar behaviour, a dose rate above a certain value would trigger crystallization and subsequent evolution of the oxygen molecules produced by previous 
irradiation, since the eutectic $\mathrm{H}_{2} \mathrm{O}_{2} \cdot \mathrm{H}_{2} \mathrm{O}-\mathrm{H}_{2} \mathrm{O}_{2}$ melting temperature is reached by spontaneous crystallization during warmup.

Condensed $\mathrm{H}_{2} \mathrm{O}_{2}$ vapour that had previously been subjected to electrodeless discharge has been shown to evolve $\mathrm{O}_{2}$ from the solid during warmup at about $160^{\circ} \mathrm{K}$ (cf.our value $\mathrm{T}_{\mathrm{X}}=165^{\circ} \mathrm{K}$ ). This fact has been explained by the formation of peroxyhydrates $\mathrm{O}_{2} \cdot \mathrm{nH}_{2} \mathrm{O}_{2}$ with values of $\mathrm{n}$ as low as three.(8) The oxygen evolution was later proved to be irreversible, since $\mathrm{O}_{2}$ could not be absorbed upon recooling the deposit. (9)

We have obtained, in addition, experimental evidence pointing to substitutional $\mathrm{O}_{2}$, probably hydrogen bonded to $\mathrm{H}_{2} \mathrm{O}_{2}$ units, as the stable damage at $77^{\circ} \mathrm{K}$. (10) Prolonged irradiation followed by a sudden increase in the dose rate could therefore provoke a foreseeable disaster were the hydrogen peroxide stored as a glass. As a matter of fact, samples that had been irradiated for rather long periods of time in our Laboratory have frequently exploded during warmup. It should be borne in mind also that, even if the propellant is well crystallized, very large doses at low temperature are likely to produce partial vitrification as they would induce partial crystallization of crystallizable glasses. Since there is not experimental information on this field as there is, for example, on fast-neutron large irradiation doses of silica glasses, further research on the ultimate effect of ir radiation at low temperature should be done.

Other compounds like hydrazine and derivatives as well as mixtures of propellants may, or may not, present the same risks, but in a general way, whenever gaseous products are likely to be formed and remain trapped, their accumulation in a crystallizable glass may be a potential source of trouble.

\subsection{Conclusions and Recommendations}

In order to aroid the hazards described in the preceding section, 2 rules are recommended in the case of low-temperature storage of liquid propellants, namely.

and

i) provoke crystallization before storage or whenever possible:

ii) choose a propellant composition lying in the phase-diagram region of the permanent glass.

With respect to the question of how to store a propellant in view of the radiation hazards, the 2 alternatives (liquid or solid at low temperature) have advantages and disadvantages. Since in outer space even a conveniently designed tank would absorb ca. $0.03 \%$ of the total incoming solar 
electromagnetic radiation, *i.e., ca. 150 Joule/ $\mathrm{ft}^{2}-\mathrm{hr}^{1}$, ** a local cooling sys tem should be incorporated to prevent a gradual rise in temperature. In the case of liquid storage, appropriate zero-g venting systems should be incorporated to eliminate the gases formed, after an earlier separation of the 2 phases. This latter process is known to present technical difficulties in the absence of a gravitational field.

If the temperature could be kept at a sufficiently low value, however, storage of propellants in the solid state would permit less excess of propellant to account for decomposition.

\section{DAMAGE MEASUREMENT IN OUTER SPACE}

\subsection{Radiation Environment in Outer Space}

The corpuscular radiation in the vicinity of Earth is reasonably known. Total corpuscular radiation and its dependence upon energy distribution in direction, time, and altitude is, however, not well known at altitudes above $75 \mathrm{~km}$. The most important energy range from the viewpoint of radiation damage is that below one Gev, since both biological and material damage depend more strongly on the total intensity of the radiation than on its spectrum of energy. $\dagger$

In addition to the primary cosmic radiation which is believed to originate outside the solar system, there is a very important contribution by the solar nuclear activity. This radiation is partly trapped in the Van Allen belts around the Earth. Typical spectra for the inner and outer belts are:(11)

INNER BELT (ca. $3,600-\mathrm{km}$ altitude, magnetic latitude $0^{\circ}$ )

Electrons with energy greater than $20 \mathrm{kev}:$

ca. $2 \times 10^{9} \mathrm{~cm}^{-2} / \mathrm{sec}$

Electrons with energy greater than 0.2 Mev:

less than $10^{8} \mathrm{~cm}^{-2} / \mathrm{sec}$

Protons with energy greater than $60 \mathrm{Mev}$ :

ca. $2 \times 10^{4} \mathrm{~cm}^{-2} / \mathrm{sec}$

* Ultraviolet, visible, and infrared.

* * The total solar electromagnetic radiation in outer space is ca. $450 \mathrm{kJuule} / \mathrm{ft}^{2}-\mathrm{hr}^{1}$. In an orbit it would be higher because of the albedo of the central body and infrared emission. In the case of a $300-n$ mile circular orbit around the Earth, with $30^{\circ}$ inclination to the equator, Olivier and Dempster( $(1)$ have estimated the following percentages of incoming radiation: solar, $59.72 \%$; albedo, 27.04\%; and infrared, $13.24 \%$.

TThe total dose rate due to the quiescent cosmic radiation in an Earth's orbit would be of no more than $0.5 \mathrm{mr} / \mathrm{hr}$, which is just below the maximum permissible level in the absence of protection. 
OUTER BELT (ca. 16,000-km altitude, magnetic latitude $0^{\circ}$ )

Electrons with energy greater than 20 ker: ca. $10^{11} \mathrm{~cm}^{-2} / \mathrm{sec}$

Electrons with energy greater than 0.2 Mev: less than $10^{8} \mathrm{~cm}^{-2} / \mathrm{sec}$

Protons with energy greater than 60 Mev: less than $10^{2} \mathrm{~cm}^{-2} / \mathrm{sec}$.

It should be pointed out, however, that these intensitios, especially in the outer belt, are known to vary by factors of as much as a thousand.

The importance of large solar flares of protons could hardly be overemphasized since these would present serious hazards in the space environment, away from the atmospheric screening effect. There are, in addition, specific particle events that can cause huge localized damage. For example, there is the case of the stopping of a slow, heavy primary particle (carbon or heavier nuclei) in any material.

It is a matter of conjecture to estimate the radiation hazards in the outer space. It is reasonable to expect, however, that Van Allen belts exist around Venus, for example, whose magnetic field is at present estimated on the basis of the deflection of solar protons as 5 times larger than the Earth's one.(11) The hazards to be encountered during a space flight in the Solar System, however, could not be anticipated within a reasonable degree of accuracy, especially during the years of maximum solar activity.

\subsection{Measurement of Radiation Damage by Paramagnetic Resonance}

Among the techniques currently used to determine the effects of radiation in matter, electron paramagnetic resonance is one of the most sensitive. It is based on the fact that the majority of the products is paramagnetic and can therefore experience magnetic transitions under appropriate conditions. Such a technique usually involves heavy and bulky equipment if maximum sensitivity is necessary (10 11 to $10^{12}$ spins). The applicability of this method is therefore limited to the intermediate range of irradiation dose.

The number $N$ of unpaired-electron fragments of one species e.g., OH in ice-can be estimated by

$$
N=D G,
$$

where $D$ is the dose and $G$ the yield in unpaired spins of one species per unit dose. Since $G$ is commonly expressed in spins per 100 ev absorbed 
and the dose is expressed as the dose absorbed per unit mass (d), the number of spins per unit mass $(n)$ can be calculated from

$$
n=d(e v / g) G \cdot 10^{-2}
$$

or

$$
n=d(r) G \cdot 6 \cdot 10^{11}
$$

according to the units used to express the dose, i.e., ev/g or $r$, respectively.

Should the sensitivity of the equipment be of $10^{12}$ spins for a sample weighing $0.1 \mathrm{~g}$, for example, it would be possible to detect doses of ca. $20 \mathrm{r}$ with a sample G-value of ca. 1 spin per $100 \mathrm{ev.} \mathrm{Such} \mathrm{a} \mathrm{dose,} \mathrm{were} \mathrm{it} \mathrm{pro-}$ duced by the quiescent cosmic radiation alone, would represent an exposure of more than 4 years. Sudden doses due to solar flares could produce $10^{14}$ spins or more in the same probe.* Absolute minimum figures for the inner and outer Van Allen belts in the magnetic equator would be $10^{14} \mathrm{ev} / \mathrm{sec}$ and $10^{15} \mathrm{ev} / \mathrm{sec}$ per gram of water, i.e., ca. 1.5 and $15 \mathrm{r} / \mathrm{sec}$, respectively. Transits of $10 \mathrm{~min}$ through each of them would produce approximately $10^{13}$ and $10^{14}$ spins per gram, respectively. Such amounts of radicals would be difficult to detect, though their influence in living cells should be given serious consideration. It should be noted, however, that a shielding of a few grams per square centimeter would seem enough to reduce the radiation effects to a safe dose rate.

\subsection{Conclusions}

Damage measurement is a difficult task. If primary effects are to be measured - as in the case of paramagnetic resonance - the sensitivity of the device must be very high, and there may be theoretical limits that would make the job almost hopeless. This is the case of paramagnetic resonance in the $r$ ange of low doses. If the property actually measured is an amplified effect (by as much as several orders of magnitude), as is the case of photographic emulsion, in which a minor energy absorption can be developed by suitable means into large and readily measurable effects (darkening), it can be expected to achieve great sensitivity. Photographic emulsions are, however, essentially ir reversible detectors, and their use would impose some sort of mechanical device to develop exposed film (whose darkening could be measured by conventional techniques) as well as to expose fresh film at a certain rate.

\footnotetext{
*Recent results on this subject indicate that solar flares occur at an average rate of one flare per month to yield protons of energies between a few Mev and $600 \mathrm{Mev}$. The proton flux is widely variable, and the exposure dose rates are comprised between one and several thousand $\mathrm{r} / \mathrm{min}$. Durations of 24 and more hours are frequent. Under such circumstances, the total dose due to one solar flare could reach hundreds of kiloroentgen with a production of $10^{17}$ or more spins per cubic centimeter.
} 
The solution to this problem must lie in the line of solid-state electronics as an essentially reversible device that could send information on dose rates as well as on total doses. Experiments are in progress at many laboratories, and semiconductive devices with sensitivities of several hundredths of a nanoampere per doses of one roentgen per hour have already been obtained. 


\section{APPENDIX. DEFINITIONS AND UNITS}

G, yield of the radiation, defined as number of molecular fragments of one species (radicals) produced by, or as number of molecules radiolyzed by, the absorption of $100 \mathrm{ev}$ of radiation.

UNIT OF DOSE:

Electron volt $(\mathrm{ev})=1.602 \times 10^{-12} \mathrm{erg}=1.602 \times 10^{-19} \mathrm{~J}$

UNITS OF SPECIFIC DOSE:

$$
\begin{aligned}
\operatorname{Rad} & =100 \mathrm{erg} / \mathrm{g}=10 \mu \mathrm{J} / \mathrm{g} \\
\text { Roentgen }(r) & =97.4 \mathrm{erg} / \mathrm{g} \text { of water* } \\
& =6.08 \times 10^{13} \mathrm{ev} / \mathrm{g} \text { of water* }
\end{aligned}
$$

*For $\mathrm{X}$ and $\gamma$ rays in the energy region where absorption is almost entirely due to the Compton effect. 


\section{REFERENCES}

1. Olivier, J.R., and Dempster, W. E, NASA Technical Note D-559 (1961).

2. Lucien, W., NASA Technical Note D-1193 (1962).

3. Jackson, J.L., J. Chem. Phys. 31, 154 (1959).

4. Fontana, B. J., J.Chem. Phys。31, 148 (1959).

5. Siege1, S., Flournoy, J. M., and Baum, L. H., J. Chem. Phys. 34, 1782 (1961).

6. Ghormley, J. A., ORNL Chem. Div. Progress Report, 1st. sem. 1955, p. 13 .

7. Schumb, W, C., Satterfield, C. N., and Wentworth, R. L., Hydrogen Peroxide, Reinhold Publishing Company, New York (1955).

8. Edwards, J.W., and Hashman, J.S., Abstr. of Papers of Amer. Chem. Soc., 132nd Meeting, New York, New York, 1957, p.42-S.

9. Ruehrwein, R. A., Hashman, J. S., and Edwards, J. W., J. Phys. Chem. 64. $1317(1960)$.

10. McMillan, J.A., and Smaller, B., to be published.

11. Valley, S. L., Air Force Cambridge Research Laboratories 62-270, Air Force Surveys in Geophysics No. 139, Jan. 1962. 